Canadian

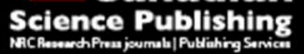

Canadian Journal of Civil Engineering Revue canadienne de génie civil

\title{
Improvements to the simplified analysis method for the design of seismically isolated bridges in CSA-S6-14
}

\begin{tabular}{|r|l|}
\hline Journal: & Canadian Journal of Civil Engineering \\
\hline Manuscript ID & cjce-2015-0427.R1 \\
\hline Danuscript Type: & Article \\
\hline Complete List of Authors: & $\begin{array}{l}\text { Koval, Viacheslav; Ministère des Transports du Québec, Direction des } \\
\text { Structures; } \\
\text { Christopoulos, Constantin; University of Toronto, Civil Engineering } \\
\text { Tremblay, Robert; École Polytechnique, Dép. de génie civil }\end{array}$ \\
\hline Keyword: & Seismic design, Bridge structures, Seismic isolation and damping \\
\hline \multicolumn{2}{|c}{} \\
\hline
\end{tabular}




\title{
Improvements to the simplified analysis method for the design of seismically isolated bridges in CSA-S6-14.
}

\author{
Viacheslav Koval ${ }^{1}$; Constantin Christopoulos M.ASCE${ }^{2}$; and Robert Tremblay ${ }^{3}$
}

\section{ABSTRACT:}

The design provisions for seismically isolated bridges in the CAN/CSA-S6 Canadian Highway Bridge Design Code and the AASHTO Guide Specifications for Seismic Isolation Design (AASHTO 2010, 2014) have been developed primarily based on ground motions recorded along the west coast of North America (NA). Both codes include a simplified analysis procedure that relies on an equivalent effective linearization of the nonlinear isolated structure together with damping coefficients to account for the effect of energy dissipation on the response of the isolated system. The appropriateness and range of application of code-specified simplified methods were investigated through nonlinear time-history analyses in order to propose improvements to this procedure for the new edition of the CSA-S6-2014 code. Based on these analyses, new damping coefficients are proposed for Eastern North America (ENA) and new limits for the application of the simplified method are defined. For ENA, the method with newly proposed damping coefficients can give good bridge displacement estimates for equivalent damping ratios of up to $40 \%$ which broadens the possible designs that can be achieved using the simplified method. This study also showed that applicability limits could be defined more accurately as a function of the system properties.

Authors keywords: Seismic design; Bridge structures; Seismic isolation and damping

\footnotetext{
${ }^{1}$ Ministry of Transportation of Quebec, Montreal, Canada

${ }^{2}$ Professor, Dept. of Civil Engineering, University of Toronto, Toronto, Canada.

${ }^{3}$ Professor, Dept. of Civil Geological and Mining Engineering, École Polytechnique, Montreal, Canada.
} 


\section{INTRODUCTION}

In 2014, major changes were introduced to the seismic design provisions for bridge structures in the CAN/CSA-S6 Canadian Highway Bridge Design Code (CSA, 2014). One of the main changes is the implementation of a multi-hazard level performance-based design method. The traditional force-based design method is only permitted for regular bridges in low seismic zones while performance-based design is now mandatory for bridges equipped with a seismic isolation system. A second important modification is that, contrary to the previous edition of the code the CSA-S6-06, in which a unique design spectrum scaled to peak ground acceleration was used, design spectra in CSA-S6-14 are constructed from site-specific uniform hazard spectral (UHS) ordinates that account for the regional differences in expected ground motion characteristics. The new spectra for the design of bridges in CSA-S6-14 are those that have been established for the 2015 NBCC (National Building Code of Canada) based on new seismological information that has been generated in the last two decades (Adams and Atkinson, 2013). Ground motion time histories representative of both eastern and western Canada have also been developed based on this more recent seismic data (Atkinson, 2009).

For the analysis and design of seismically isolated bridges, CSA-S6-14 still includes a simplified analysis method that relies on an equivalent effective linearization of the nonlinear isolated structure and equivalent viscous damping properties to account for the effect of the isolation system's energy dissipation. This method is similar to one specified in the AASHTO Guide Specifications for Seismic Isolation Design (AASHTO 2010, 2014) used in the United States. In CSA-S6, the simplified method is limited to simple bridges for which lateral seismic displacements can be estimated using a single-degree-of-freedom (SDOF) representation; however, the method is also largely used for the preliminary design of more complex structures. In view of the important changes to the seismic input data introduced in 2014 , this method had to be revisited with particular attention to the damping coefficients and its limits of applicability.

In this simplified method, damping coefficients $B$ are applied to the displacement demand obtained from a $5 \%$ damped response spectrum to predict peak displacements to account for the beneficial effect of the energy dissipation capacity of the isolation system. Values of the damping coefficients specified in previous editions of the code have been developed in the 1980's, essentially from numerical simulations of the response of 
structures subjected to ground motions from historical earthquake events that have occurred in Western North American (WNA) (Newmark and Hall, 1982; Wu and Hanson, 1989). Earthquakes in Eastern North American (ENA) have most of their energy concentrated at higher frequency when compared to WNA ground motions and therefore affect more strongly shorter period structures (Tremblay and Atkinson, 2001; Atkinson, 2009; Koval, 2015). However, no study had yet been performed to estimate damping coefficients for structures subjected to ENA ground motions, mainly because of a lack of representative historical seismic records or simulated ground motion time histories for this part of the continent. In addition, in several past studies, the coefficients $B$ have been established based on the effect of viscous damping on the response of linear oscillators, rather than from nonlinear time-history analyses (NLTHA) accounting for the actual nonlinear response of bridge isolation systems that is the source of the energy dissipation in the system. Therefore, damping coefficients $B$ in CSA-S6 were defined only as a function of the system equivalent damping without accounting for the effective period of the linearized effective system.

The appropriateness of using the same damping coefficients for both WNA and ENA ground motions has been questioned in past studies (Taylor, 1999; Naumoski, 2000). The accuracy of the simplified method has been extensively studied using linear time-history analyses in past studies worldwide and different factors of influence have been reported. In particular, dependency of damping reduction coefficients on the bridge effective period has been identified in previous work (e.g., Hwang, 1996; Lin and Chang, 2003; Atkinson and Pierre, 2004; Dwairi and Kowalsky, 2004; Weitzmann et al., 2006; Hatzigeorgiou, 2010; Koval et al., 2012; Koval, 2015). Lin and Chang (2004), Cameron and Green (2007), and Stafford et al. (2008) also examined the effects of site classes on damping coefficients. Bommer and Mendis (2005) found that damping effects may also vary with earthquake magnitude and distance as well as with soil types. Local site effects on damping coefficients were studied by Bradley (2015) and Koval (2015). Dicleli and Buddaram (2007) proposed expressions for the effective damping ratio that indirectly account for the intensity and frequency characteristics of the ground motion.

The use of site-specific UHS ordinates in CSA-S16-14 represents a major improvement to account for local seismic hazard conditions. For isolated bridges, however, the benefits resulting from this improvement would have been only partial if a unique set of damping coefficients ignoring site-specific frequency characteristics of 
ground motions on the damping of spectral displacements was specified for both eastern and western regions of the country.

Further, in CSA-S6-06, the application of the simplified method in the final design of isolated bridges was limited to systems exhibiting $30 \%$ or less equivalent damping. The 2010 AASHTO Guide Specifications for Seismic Isolation Design also prescribed that the method could not be used for bridges with an effective period longer than 3 seconds. For isolated bridges exceeding these limits, the use of an equivalent linearization was deemed not to properly represent the effect of isolation on the structural response and nonlinear response history analysis was therefore required (AASHTO, 2009). These limitations have been found to be too restrictive for certain cases of practical isolation applications (Medeot, 2004; 2012) and therefore also needed to be revisited.

This article presents an extensive numerical study that was performed to develop new damping coefficients and application limits for the CSA-S6-14 simplified analysis method for seismically isolated bridges. The simplified, linearization method as specified in the previous CSA-S6-06 code is first outlined. The methodology that was used to establish the damping coefficients is then described. The study was performed for two densely populated Canadian cities: Vancouver, British Columbia, and Montreal, Quebec. These two locations are representative of other large cities located in moderate seismic regions such as Seattle and Portland in WNA and Boston or New York in ENA. For both locations, new damping coefficients are obtained by comparing the response of NLTHA to results obtained using the code simplified analysis method. Site-specific seismic data and ground motions were used in the nonlinear time-history analyses and the study was performed for a wide range of isolated bridges. In the last section of the paper, new limits for the application of the simplified method for final design are proposed in terms of equivalent damping ratios as well as system properties.

\section{CSA-S6 SIMPLIFIED ANALYSIS PROCEDURE}

In CSA-S6, the simplified analysis method can be used to compute the peak displacements of simple isolated bridges responding essentially in their fundamental vibration mode. The method can be applied for a variety of seismic isolation systems. Herein, it is illustrated for bridges equipped with elastomeric or sliding isolators, which represent the vast majority of isolated bridge applications in NA. The horizontal force-displacement 
response of such bridges can be idealized by a bilinear hysteresis as shown in Fig. 1a (Skinner et al., 1993; Constantinou et al., 1993; Naeim and Kelly, 1999; and Dion et al., 2012).

The simplified method is based on the transformation of the actual nonlinear isolated structure into an equivalent linear system that has effective stiffness $k_{\text {eff }}$ and period $T_{\text {eff }}$ and equivalent linear viscous damping ratio $\beta_{\text {eff. }}$ (Fig. 1a). These properties are determined at the maximum expected displacement $u_{\max }$ In CSA-S6, the equivalent damping ratio of the isolated bridge includes the inherent damping of the substructure, $\beta_{i}$, the hysteretic damping of the isolation system, $\beta_{h}$, and the supplemental viscous damping, $\beta_{v}$, if any. It can be estimated from (Tsopelas et al., 1997; Koval et al., 2012b; Koval, 2015):

$$
\beta_{\text {eff }}=\beta_{i}+\beta_{h}+\beta_{v}
$$

where $\beta_{h}$ is established from the energy dissipated per cycle, $E_{h}$, when the isolated bridge is subjected to harmonic oscillations at maximum displacement, $u_{\max }$ (Fig. 1a):

$$
\beta_{h}=\frac{1}{2 \pi}\left(\frac{E_{h}}{k_{\text {eff }} u_{\max }^{2}}\right)
$$

and $\beta_{i}$ is usually set equal to $5 \%$ unless a different inherent damping is specified.

In the previous CSA-S6-06 code, the peak displacement across the isolation bearings, $u_{\text {max }}$, was obtained from:

$$
u_{\max }=\left(\frac{T_{\text {eff }}}{2 \pi}\right)^{2} \frac{A S_{i}}{B T_{\text {eff }}} g \approx \frac{250 A S_{i} T_{\text {eff }}}{B}(\mathrm{~mm})
$$

where $A$ is the zonal acceleration ratio, $S_{i}$ is the site coefficient, and $B$ is the damping coefficient. The acceleration ratio corresponds to peak ground acceleration normalized to acceleration due to gravity, $g$ $\left(=9810 \mathrm{~mm} / \mathrm{s}^{2}\right)$. The equation assumed that the peak horizontal acceleration of an elastic oscillator with $5 \%$ damping decreases as a function of the inverse of the effective period, regardless of the regional seismicity. The displacement of the isolated bridge is computed by dividing the $5 \%$ damped elastic displacement response by the damping coefficient $B$ which corresponds to the ratio between the $5 \%$ damped response to the response for the equivalent damping ratio $\beta_{\text {eff }}$ (Fig. 1C). In CSA-S6-06, values of $B$ were specified for values of $\beta_{\text {eff }}$ between $2 \%$ and $50 \%$, as shown in Table 1 . For intermediate $\beta_{\text {eff }}$ values, $B$ could be determined by linear interpolation between the prescribed values. 
The method is an iterative procedure as the peak displacement must be known to determine the effective structure properties that are then used to estimate peak displacements. Once convergence is achieved, the design seismic force for the substructure is determined from the load-displacement response of the actual nonlinear isolation system at the peak displacement. As previously mentioned, in CSA-S6-06, the method was only permitted for values of $\beta_{\text {eff }}$ not exceeding $30 \%$. For systems with higher damping, peak displacements and forces had to be determined using nonlinear time-history analysis, unless $B$ was limited to $1.7\left(\beta_{\text {eff }}=30 \%\right)$ in the calculations. The bridge isolators also had to develop minimum restoring force capacity corresponding to $2.5 \%$ of the superstructure weight when displaced by $50 \%$ of the peak displacement.

In the United Sates, the AASHTO Guide Specification for Seismic Isolation Design (AASHTO 2010, 2014) proposes the same simplified method except that the $5 \%$ damped elastic design spectrum is constructed using a two-point method depending on the site-specific design spectral values $S_{S}$ and $S_{1}$ at periods of 0.2 and $1.0 \mathrm{~s}$, respectively. In AASHTO, damping coefficients are calculated from:

$$
B=\left(\frac{\beta_{\text {eff }}}{5 \%}\right)^{n}
$$

where the exponent $n$ is set to 0.3. Interpolation between tabulated values is therefore no longer required. Damping coefficients from this equation are nearly the same as specified in CSA-S6-06, as shown in Fig. 2. AASHTO also specifies that the simplified method cannot be used if the effective period exceeds $3 \mathrm{~s}$.

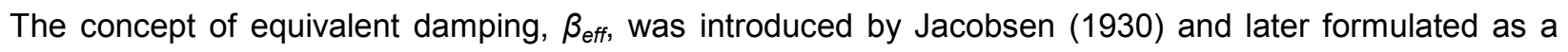
function of dissipated energy, $E_{h}$ (Jacobsen, 1960). Gulkan and Sozen (1974) used it to define a substitute linear structure with a fictitious equivalent damper, as presented in Fig. 1a, and the concept was later incorporated in seismic provisions as a simplified design method. Guidelines for the design of seismic isolation systems were first published by the Structural Engineers Association of Northern California (SEAONC, 1986). The damping coefficient $B$, first appeared in the 1991 UBC (ICBO) provisions for base-isolated buildings (Naeim et Kircher, 2001). The values of B specified in CSA-S6-06 have been derived based on the work of Newmark and Hall (1982) using results obtained for structures with periods in the velocity region of the ground-motion spectra (Table 1). In these early studies, spectrum amplification factors were computed for different damping levels using the elastic response of a viscously damped SDOF system. Over the years, the 
equivalent linear system approach with equivalent damping has been adopted in several codes and the different values of damping coefficients that have been adopted are given in Table 1 and Fig. 2 for comparison.

In the new CSA-S6-14 code, the design spectrum is based on the $5 \%$ damped uniform hazard spectral ordinates established for the National Building Code of Canada (NBCC). At a given effective period, the design displacement spectral value, $S_{\mathrm{d}}\left(T_{\text {eff }}\right)$, is obtained from:

$$
S_{d}\left(T_{\text {eff }}\right)=\left(\frac{T_{\text {eff }}}{2 \pi}\right)^{2} S\left(T_{\text {eff }}\right) g
$$

The peak displacement of the isolated bridge is then computed by dividing the elastic spectral displacement response $S_{d}\left(T_{\text {eff }}\right)$ by the damping coefficient $B$, which corresponds to the ratio between the $5 \%$ damped response and the demand for the effective damping ratio $\beta_{\text {eff }}$ (Fig. 1c).

\section{NEW DAMPING COEFFICIENTS FOR CSA-S6-14}

\section{Seismic Data and ground motions}

The study presented herein was performed for Vancouver, BC, and Montreal, QC, to represent the WNA and ENA seismic regions, respectively. Site class C (soft rock or firm ground) was considered at both sites. For Vancouver, the hazard from crustal and sub-crustal earthquakes was considered and subduction earthquake effects were omitted. In CSA-S6-14, the design spectra are based on the uniform hazard spectral (UHS) ordinates for the 2015 edition of the National Building Code of Canada (NBCC). This data was not available at the time of the study and UHS values, $S_{a}(T)$, established for the 2005 NBCC $($ NRCC, 2005) were used as seismic input for the investigation. In this code, the design spectrum $S(T)$ for a class $C$ site is equal to $S_{a}(0.2$ s) for period $T$ less than and equal to $0.2 \mathrm{~s}$, the lesser of $S_{a}(0.2 \mathrm{~s})$ and $S_{a}(0.5 \mathrm{~s})$ for $T=0.5 \mathrm{~s}, S_{a}(1.0 \mathrm{~s})$ for $T=$ $1.0 \mathrm{~s}, S_{\mathrm{a}}(2.0 \mathrm{~s})$ for $T=2.0 \mathrm{~s}$, and $0.5 \mathrm{~S}_{\mathrm{a}}(2.0 \mathrm{~s})$ for $T$ equal to or longer than $4.0 \mathrm{~s}$. Linear interpolation is used for intermediate period values. The design spectra at the two sites are presented in Fig. 3. As can be seen in the figure, ground motions in ENA have shorter dominant periods and lower spectral ordinates for longer periods than in WNA, leading to smaller displacement demands.

For each site, a suite of twenty site representative simulated ground motion time histories developed by 
Atkinson (2009) was used. Ground motions in that database were generated for small-to-moderate and moderate-to-large events having, respectively, moment magnitudes M6.5 and M7.5 for WNA and M6 and M7 for ENA. The time histories of these events were regrouped by two distance ranges of 10-15 km and 20-30 km for small-to-moderate earthquakes and of $15-25 \mathrm{~km}$ and $50-100 \mathrm{~km}$ for moderate-to-large earthquakes, resulting in four subsets defined in terms of magnitudes and distances. For each suite, the time histories were selected from these subsets according to magnitude-distance (M-R) scenarios dominating the seismic hazard at the sites, as obtained from de-aggregation of the seismic hazard for a probability of exceedance of $2 \%$ in 50 years (Halchuk and Adams, 2004; Halchuk, 2009). The resulting suites are denoted as ATK-W for WNA and ATK-E for ENA. The amplitude of the ground motions were linearly scaled to match the design spectra $S(T)$ over the 0.2 to 4.0 s period range; the scaling factor being equal to the mean values of the ratios between $S(T)$ and the $5 \%$ damped ground motion acceleration spectral values, $S_{\mathrm{ag}}(T)$, computed at equally spaced period increments in the period range. For each M-R scenario, the records from the database with the lowest standard deviation of $S / S_{\text {ag }}$ ratios were selected to build the suite of 20 records. The $5 \%$ damped acceleration, $S_{\mathrm{ag}}$, and displacement, $S_{\mathrm{d}}$, spectra of the selected records are compared to the respective design spectra in Fig. 3. As presented in Fig. 4, an excellent match was obtained between the mean spectra of the scaled ground motions and the design spectra.

\section{Nonlinear time-history analyses (NLTHA)}

NLTHA of SDOF systems exhibiting the bilinear hysteretic response described in Fig. 1a was performed to determine peak displacement values $u_{N L T H}$. The bridge parameters used in the study are presented in Table 2: $R$ is the response modification factor, which corresponds to the ratio between the activation lateral force and the elastic force demand, $T_{\mathrm{e}}$ is the initial (elastic) period of the non-isolated bridge, $\xi$ is the inherent damping defined using initial and effective periods of the bridge, and $\alpha$ is the ratio between the post-elastic and the initial (elastic) structure stiffness $k_{\mathrm{d}} / k_{\mathrm{e}}$ (Fig. 1a). For convenience in the study, $R$ was taken equal to the ratio $u_{\mathrm{e}} / u_{\mathrm{y}}$ where $u_{\mathrm{e}}$ is the elastic displacement from the design spectrum, $u_{\mathrm{e}}=S_{d}\left(T_{\mathrm{e}}\right)$, and $u_{\mathrm{y}}$ is the displacement at activation of the isolator (Fig. 1a). As shown in Table 2, various inherent damping levels were considered based on both the initial and effective periods. The parameters studied were changed, one at a time, to obtain 300 isolated bridge configurations: $5(R) \times 4\left(T_{e}\right) \times 5(\xi) \times 3(\alpha)$. Each of these isolation systems were analyzed under 20 time-history records representative of the WNA and ENA regional seismicity (40 NA 
records), resulting in a total of $12,000 \mathrm{NLTHA}$. For each bridge, $u_{N L T H}$ was taken equal to the mean value of the peak displacements from the 20 times histories.

\section{Evaluation of the Damping Coefficients of CSA-S6-06}

Damping coefficients from the previous CSA-S6-06 code were first evaluated by comparing the $5 \%$ damped spectral displacements to the NLTHA results. For each bridge structure at each site, a damping coefficient value was determined for each ground motion from:

$$
B=\frac{S_{d}\left(T_{\text {eff }}\right)}{u_{N L T H}}
$$

For each ground motion, the effective properties $k_{\text {eff, }}, T_{\text {eff }}$ and $\beta_{\text {eff }}$ were determined by setting $u_{\max }=u_{\mathrm{NLTH}}$. Mean $B$ and $\beta_{\text {eff }}$ values from the 20 ground motions were computed for each bridge at each site and the results are presented in Fig. 5. In this figure, the damping coefficient obtained from Eq. 4 with $n=0.3$ is also plotted for comparison with the CSA-S6-06 coefficients. As sown in Fig. 5, for WNA, the majority of the $B$ coefficients are greater than the values obtained from Eq. 4, which shows that the equation generally results in conservative (larger) response estimates. In contrast, for the ENA records in Fig. 5b, a large portion of the points are lower than the curve obtained from Eq. 4, especially for $\beta_{\text {eff }}$ greater than $10 \%$, indicating unconservative predictions when using the CSA-S6-06 $B$ factors. The observed differences between $B$ coefficients at the two sites are primarily attributable to the differences in the ground motion characteristics in WNA and ENA.

To further examine the adequacy of the B-coefficients in CSA-S6-06, the displacements predicted using these coefficients in the code simplified analysis method of CSA-S16-14 are compared to displacements obtained through NLTHA, $u_{\mathrm{NLTH}}$. In CSA-S6-14, the maximum displacement is obtained from the site specific design displacement spectra $S_{d}(T)$ :

$$
u_{\text {code }}=\frac{S_{d}\left(T_{\text {eff }}\right)}{B}
$$

Values of $u_{\text {code }}$ were determined for the 300 bridge structures at both sites and compared in Fig. 6 with the mean $u_{N L T H}$ for the 20 ground motions. In Fig. 6a, the code predictions for WNA are generally very close and slightly greater than the corresponding $u_{N L T H}$ values, indicating that the CSA-S6-14 simplified method with 
damping coefficients from Eq. 4 with $n=0.3$ is appropriate for WNA. For ENA (Fig. 6b), a large fraction of the code predictions are smaller than the NLTHA results, especially for systems exhibiting a low post-yield stiffness ratio ( $\alpha \leq 0.05$ ), which provides further evidence that the CSA-S6-06 code B-coefficients required modifications for ENA in CSA-S16-14.

\section{Proposed B Values for CSA-S6-14}

The NLTH analysis results are examined from a statistical point of view to propose values of the $B$ coefficients for CSA-S6-14. More specifically, the probability density functions of the ratio $u_{N L T H} / u_{\text {code }}$ are studied. The results are presented in Fig. 7 for three subsets of 60 bridges for each site. Each subset was composed of the bridges having the five $R$, four $T_{e}$ and three $\xi\left(T_{\text {eff }}\right)$ values shown in Table 2 that are grouped using the values of $\alpha: 0.01,0.05$ or 0.10 . Values in the plots were therefore computed for a statistical sample of 1200 responses of the 60 different isolated bridge structures analyzed under 20 time-history records. There were 20 responses from NLTHA for one response estimate from the CSA-S6-06 simplified method. The vertical axis of these plots represents the number of times a particular value of the ratio between the peak displacements obtained from NLTHA and peak displacements obtained using the CSA-S6-06 simplified method ( $\left.\mathrm{U}_{\mathrm{NLTH}} / \mathrm{u}_{\mathrm{code}}\right)$ occurs within a given statistical sample.

Visual inspection indicates that all probability density functions are close to a normal distribution with a generally symmetrical bell curve and the highest point close to the center. It is further confirmed that the data is well described by a Normal distribution by comparing the cumulative probabilities of the data sets. For instance, as shown in the figure, the cumulated probability of the $u_{N L T H} / u_{\text {code }}$ ratios vary between $85.2 \%$ and $86.5 \%$ for the range extending from zero to mean+one standard deviation $(\bar{x}+\sigma)$ value, which is close to the $84 \%$ cumulated probability for a normally distributed sample.

Assuming that the sample of $u_{N L T H} / u_{\text {code }}$ ratios from the analyses is normally distributed, the upper bound of a 95\% confidence interval for the mean $u_{N L T H} / u_{\text {code }}$ ratio, $x$, can be obtained from:

$$
x=\bar{x}+1.645 \frac{\sigma}{\sqrt{m}}
$$

where $\bar{x}, \sigma$, and $m$ are the mean, standard deviation and size of the sample. The calculations are performed herein for the group of bridges with $\alpha=0.01$ for which $\bar{x}$ is highest at the two sites, thus representing the 
most critical condition. For this sample, $m=1200$ (60 bridges $\times 20$ ground motions) and the resulting statistics are given in Table 3. For the WNA site, the mean $u_{N L T H} / u_{\text {code }}$ ratio is equal to 1.01 , which indicates that the simplified method with the damping coefficient from Eq. 4 and $n=0.3$ gives, on average, good peak displacement estimates. For ENA, the corresponding value is 1.32, indicating that the method would produce, on average, non-conservative results with these damping coefficients. The procedure was repeated for this site by varying the exponent $n$ in Eq. 4 and it was found that using $n=0.2$ for the ENA site results in an expected mean $u_{N L T H} / u_{\text {code }}$ ratio equal to 1.0 (Table 3), comparable to the value for WNA. Eq. 4 was therefore proposed and incorporated in CSA-S6-14 with two different exponent values: $n=0.2$ for ENA and $n=0.3$ for WNA. In this way, the same level of accuracy is anticipated in both regions of the country.

\section{LIMITS OF APPLICATION FOR THE SIMPLIFIED METHOD}

In Fig. 8 , the mean $u_{N L T H} / u_{\text {code }}$ ratios are plotted against the equivalent damping $\beta_{\text {eff. }}$ In this figure, $u_{\text {code }}$ is determined using the damping coefficients proposed in the previous section. As shown, the simplified method underestimates peak displacements for a number of cases when $\beta_{\text {eff }}$ is large. As mentioned, the simplified method in CSA-S6-06 was not permitted when the equivalent viscous damping was greater than $30 \%$. The results in Fig. 8 show that this limit would still be appropriate for WNA but too restrictive for ENA. In CSA-S614 , the limit of $30 \%$ was therefore maintained for WNA but was extended to $40 \%$ for isolated bridges located in ENA.

In Fig. 8, it is also evident that these limits on $\beta_{\text {eff }}$ prohibit the use of the simplified method for a large number of isolated bridges for which the method gives conservative displacement estimates, suggesting that these limits are too restrictive for certain cases of practical applications, as was observed in previous studies (Medeot, 2004; Medeot, 2012). Close examination of the nonlinear response of the bridges for which $u_{N L T H} / u_{\text {code }}$ exceeds 1.0 shows that the peak displacement is increased by a permanent shift of the center of oscillation of the structure that occurs during the earthquake, a phenomenon that cannot be accounted for when using an equivalent linear system which is centered about the origin to predict nonlinear response. This shifting of the oscillation center is illustrated in Fig. 9 for one of the cases studied. This response is not adequately predicted with the equivalent linear model, which results in underestimated peak displacements. This behaviour generally occurs under large acceleration pulses contained in ground motion signals (Iwan, 1961; Kawashima et al., 1998; Graizer, 2010). The peak displacement in these cases is more influenced by 
the transient response under the acceleration pulse rather than by the system damped steady-state response about the zero deformation position, as is assumed for an equivalent linear system. Moreover, as illustrated in Fig. 10, a structure that has experienced a shift of its oscillation center is expected to dissipate significantly less energy when responding about the shifted center of oscillation compared to the energy dissipated by the same system oscillating about the origin when reaching the same peak displacement. The second case corresponds to the assumption made in the simplified method, which indicates that the method overestimates the system energy dissipation capacity in cases where the center of oscillation is displaced.

A closer inspection of these results also shows that displacement under-prediction is more frequent for isolation systems designed with a higher activation load and the response is limited to a few nonlinear excursions, rather than isolation systems that are mobilized at lower activation forces and sustain several oscillations with large nonlinear displacements. In the former case, the response deviates more from the assumption of a cyclic inelastic response about a centered position. This behaviour is reflected in Fig. 11 where the ratio $u_{N L T H} / u_{\text {code }}$ is plotted against $u_{\text {code }} / S_{d}$. The influence of the post-activation stiffness in terms of three different $\alpha$ ratios is also shown in the figure. As shown, the displacement is underestimated for cases where $u_{\text {code }} / S_{d}$ is small. On this basis, it was defined that the simplified method in CSA S6-14 is not permitted when it predicts displacements that are too small, by specifying a minimum displacement value:

$$
u_{\text {code }} / S_{d} \geq 1.5
$$

In Fig. 11, it can also be seen that under-prediction is more pronounced for smaller values of $\alpha$ and the above limit need not be applied when the isolation system has a minimum post-activation stiffness as defined by the prescribed minimum restoring force capacity.

For a given bilinear system, the relation between the energy dissipation per cycle, $E_{\mathrm{h}}$, and the peak displacement $u_{\max }$ can be obtained from the shape of the hysteretic curve (see Fig. 2a). Using Eq. 5, this relation can be transformed into a relation between $\beta_{\text {eff }}$ and the system effective period, $T_{\text {eff. }}$ An example is plotted in Fig. 12. As shown, $\beta_{\text {eff }}$ gradually increases with $T_{\text {eff, }}$ attains a maximum when $T_{\text {eff }}$ reaches the value $T_{\mathrm{e}} \alpha^{-0.25}$, and then gradually diminishes. Hence, equivalent linear systems representing isolated bridges have the same equivalent damping $\beta_{\text {eff }}$ for two different effective periods or peak displacements. Further 
investigation of the nonlinear response of the bridges for which unconservative estimates were obtained in Fig. 8 revealed that displacements were underestimated essentially for the cases where $T_{\text {eff }}$ was smaller than $T_{\mathrm{e}} \alpha^{-}$ 0.25 . Conversely, the simplified method gave conservative displacement estimates for all cases where $T_{\text {eff }}>T_{\mathrm{e}} \alpha^{-0.25}$, even if $\beta_{\text {eff }}$ was similar. This is illustrated in Fig. 13. The scatter in the predicted displacements for each ground motion is also consistently higher when $T_{\text {eff }}<T_{\mathrm{e}} \alpha^{-0.25}$ (Fig. 14). Additional details on this formulation and interpretation of these results can be found in Koval (2015). These observations indicate that $\beta_{\text {eff }}$ may not be the most appropriate parameter to determine the accuracy of the simplified method. Systems with high equivalent damping and relatively short effective periods are those for which the linearization assumption is the least accurate for displacement predictions. These are systems for which small inelastic excursions are predicted by the simplified method. On this basis, it is suggested that the simplified method could be permitted if:

$$
T_{\text {eff }} \geq T_{e} \cdot \alpha^{-0.25}
$$

Further validation of this new limit is required before it can be adopted in codes however. Meanwhile, this recommendation has been introduced as a complement of information in the Commentary to CSA-S6-14.

In the 2014 AASHTO Guide Specification for Seismic Isolation Design, the simplified method is not permitted when the effective period of the isolated bridge is longer than $3 \mathrm{~s}$. As shown in Fig. 13a, this study confirmed that the simplified method may underestimate bridge displacements when $T_{\text {eff }}$ is excessively long. As such, the period limit specified in AASHTO was adopted in CSA-S6-14.

\section{CONCLUSIONS}

As part of the effort towards developing the new edition of the Canadian Highway Bridge Design Code (CSAS6-2014) a study was carried out in order to investigate the validity of damping coefficients $B$ specified in CSAS6-06 and AASHTO 2010 for the design of isolated bridges in ENA and WNA. These coefficients had been established based on the response of structures subjected to ground motions from historical earthquake events that have occurred in WNA. In this study, the appropriateness of the damping coefficients $B$ was investigated using NLTH analysis that accounted for the actual nonlinear response of bridge isolation systems under site-specific time-history records for each of the WNA and ENA regions. A series of nonlinear system parameters was considered to cover a wide range of isolated bridge configurations. 
The damping coefficients specified in CSA-S6-06 and AASHTO 2010 codes were found to predict well the peak displacements of isolated bridges in WNA but underestimated the displacement demand of bridges subjected to ENA seismic ground motions. Based on these results, a new value was proposed for the exponent to be used for ENA in the equation currently specified in the AASHTO specifications for the damping coefficient so that the same equation can be used with different exponents for WNA and ENA locations. The AASHTO equation for the damping coefficient with two different exponent values was adopted for CSA-S6-14.

For both NA seismic regions (ENA and WNA), the limits of application of the simplified method were examined. The current limit of $30 \%$ for the equivalent damping ratio was maintained for WNA but was relaxed to $40 \%$ for ENA. NLTH analysis also showed that displacements were not well predicted by the simplified method for systems having low post-activation stiffness when the ratio between code predicted and spectral displacements was less than 1.5. The study also identified a new limit on the effective period that more consistently predicts cases where the simplified method is likely to underestimate bridge peak displacements. This limit is based only on the bridge initial (non-isolated) period and the post-activation stiffness ratio of the isolation system. The results also confirmed that an upper limit on effective period as currently prescribed in AASHTO is warranted.

\section{ACKNOWLEDGMENTS}

This work was supported by the Natural Science and Engineering Research Council of Canada (NSERC) as part of the Canadian Seismic Research Network's (CSRN) project and by the doctoral research scholarship from the Fonds Québécois de la Recherche sur la Nature et les Technologies (FQRNT). 


\section{REFERENCES}

AASHTO. (2009). "AASHTO Guide Specifications for LRFD Seismic Bridge Design, $1^{\text {st }}$ ed." American Association of State Highway and Transportation Officials (AASHTO), Washington, DC, USA.

AASHTO. (2010). "Guide Specifications for Seismic Isolation Design, 3rd ed." American Association of State Highway and Transportation Officials (AASHTO), Washington, DC, USA.

AASHTO. (2014). "Guide Specifications for Seismic Isolation Design." $4^{\text {th }}$ ed., American Association of State Highway and Transportation Officials (AASHTO), Washington, DC, USA.

Atkinson G.M., and Adams, J. (2013). "Ground motion prediction equations for application to the 2015 Canadian national seismic hazard maps", Can. J. Civ. Eng., 40(10), 988-998.

Atkinson G.M., and Pierre, J.R. (2004). "Ground motion response spectra in Eastern North America for different critical damping values." Seismol. Res. Lett., 75(4), 541-545.

Atkinson G.M. (2009). "Earthquake time histories compatible with the 2005 National Building Code of Canada uniform hazard spectrum", Can. J. Civ. Eng., 36(6), 991-1000.

Bommer, J.J. and Mendis, R. (2005). "Scaling of spectral displacement ordinates with damping ratios". Earthquake Eng. and Struct. Dyn., 34(2): 145-165.

Bradley, B.A. (2015). "The influence of source- and site-specific effects on response spectrum damping modification factors." Earthquake Spectra, http://dx.doi.org/10.1193/070213EQS189M

CSA. (2006). CAN/CSA-S6-06, Canadian Highway Bridge Design Code. Canadian Standards Association (CSA), Mississauga, ON, Canada.

CSA. (2014). S6-14, Canadian Highway Bridge Design Code. Canadian Standards Association (CSA), Mississauga, ON, Canada.

Cameron, W.I., Green, R.U. (2007). "Damping correction factors for horizontal ground-motion response spectra." Bull. Seism. Soc. Am., 97(3) 934-960.

CEN. (2005). "Eurocode 8: Design Provisions for Earthquake Resistance of Structures. Part 2: Bridges." EN 1998-2:2005, Comité européen de normalisation (CEN), Brussels, Belgium.

Chopra, A. K. (2007). "Dynamics of structures, theory and applications to earthquake engineering." 3rd Ed., Pearson Prentice-Hall, Upper Saddle River, N.J.

Dicleli, M., and Buddaram, S. (2007). "Comprehensive evaluation of equivalent linear analysis method for 
seismic-isolated structures represented by sdof systems." Engineering Structures, 29, 1653-1663.

Dwairi, H., and Kowalsky, M. (2004). "Investigation of Jacobsen's equivalent viscous damping approach as applied to displacement-based seismic design." Proc. $13^{\text {th }}$ World Conf. on Earthquake Eng., Vancouver, BC, Canada. Paper No. 228.

Gulkan, P. and Sozen, M. (1974). "Inelastic response of reinforced concrete structures to earthquakes motions." ACI J., 71(12) 604-610.

Halchuk, S., and Adams, J. (2004). "Deaggregation of seismic hazard for selected Canadian cities." Proc. $13^{\text {th }}$ World Conference on Earthquake Engineering, Vancouver, Canada, August 1-6, 2004, Paper No. 2470. Halchuk, S. (2009). Personal Communication.

Hatzigeorgiou, G.D. (2010). "Damping modification factors for SDOF systems subjected to near-fault, far-fault and artificial earthquakes", Earthquake Eng. and Struct. Dyn., 39 (11), 1239-1258.

Hwang, J.S. (1996). "Evaluation of equivalent linear analysis methods of bridge isolation." Journal of Structural Engineering, ASCE, 122, 8, 972-976.

ICBO (1991). "Uniform Building Code." International Conference of Building Officials, California, USA.

Jacobsen, L.S. (1930). "Steady Forced Vibrations as Influenced by Damping." ASME Transactions, 52, 169181.

Jacobsen, L.S. (1960). "Damping in Composite Structures." Proc. of 2nd World Conference on Earthquake Engineering, Tokyo and Kyoto, Japan, 1029-1044.

Koval, V., Tremblay, R. and Christopoulos, C. (2012a). "Isolation and Damping Mitigation Strategies for Bridges in Western and Eastern North America." Proc. of $15^{\text {th }}$ World Conference on Earthquake Engineering, Lisbon, Portugal, Paper No. 898.

Koval, V., Christopoulos, C., and Tremblay, R. (2012b). "Analytical Model for Optimizing the Design of Isolated and Damped Bridge Structures", Proc. of 29th International Bridge Conference, June 10-13, Pittsburgh, Pennsylvania, US, Paper IBC-12-106.

Koval, V. (2015). "Improved Simplified Methods for Effective Seismic Analysis and Design of Isolated and Damped Bridges in Western and Eastern North America." Ph.D. dissertation, University of Toronto, Toronto, ON.

Lin, Y.Y., and Chang, K.C. (2003). "Study on Damping Reduction Factor for Buildings under Earthquake 
Ground Motions." J. Struct. Eng., ASCE, 129(2): 206-214.

Lin, Y.Y., and Chang, K.C. (2004). "Effects of Site Classes on Damping Reduction Factors." J. Struct. Eng., ASCE, 130(11):1667-1675.

Naeim, F., and Kircher, C.A. (2001). "On the damping adjustment factors for earthquake response spectra." The Structural Design of Tall Buildings, 10(5), 361-369.

Naumoski, N., Cheung, M.S., and Foo, S. (2000). "Evaluation of the seismic response coefficient introduced in the Canadian Highway Bridge Design Code." Can. J. Civ. Eng., 27 (6), 1183-1191.

Newmark, N.M. and Hall, W.J. (1982). "Earthquake spectra and design." Earthquake Engineering Research Institute, Oakland, U.S.A.

NRCC. (2005). "National Building Code of Canada, $12^{\text {th }}$ ed., and Commentary". National Research Council of Canada, Ottawa, ON, Canada.

SEAONC. (1986). "Tentative Seismic Isolation Design Requirements." Structural Engineers Association of Northern California (SEAONC), San Francisco, CA.

Stafford, P.J., Mendis, R. and Bommer J.J. (2008). “Dependence of damping correction factors for response spectra on duration and numbers of cycles." J. Struct. Eng. ASCE, 134(8): 1364-1373.

Taylor, P.R. (1999). "Some thoughts on seismic engineering for bridges seen from a Canadian perspective." Proc. $8^{\text {th }}$ Canadian Conference on Earthquake Engineering, Vancouver, BC, 29-41.

Tremblay, R., and Atkinson, G.-M. (2001). "Comparative Study of the Inelastic Seismic Demand of Eastern and Western Sites." Earthquake Spectra, 17(2): 333-358.

Tsopelas, P., Constantinou, M.C., Kircher, C.A., and Wittaker, A.S. (1997). "Evaluation of Symplified Methods of Analysis for Yielding Structures", Technical Report NCEER-97-0012, State University of New York, Buffalo, New York, US, 48 p.

Weitzmann, R., Ohsaki, M., and Nakashima. M. (2006). "A Simplified methods for design of base-isolated structures in the long-period high-damping range." Earthquake Engineering and Structural Dynamics, 35: 497-515.Wu, J., and Hanson, R.D. (1989). "Study of inelastic spectra with high damping." J. of Struct. Eng., ASCE. 115(6): 1412-1431. 


\section{List of Tables:}

Table 1: Values of the Damping Coefficient, $B$

\begin{tabular}{|c|c|c|c|c|c|c|c|c|}
\hline \multirow{2}{*}{$\begin{array}{c}\beta \\
(\%)\end{array}$} & \multicolumn{2}{|c|}{$\begin{array}{c}\text { Newmark \& Hall } \\
(1982)\end{array}$} & \multirow{2}{*}{$\begin{array}{c}\text { UBC } \\
(1994) \\
\text { B }\end{array}$} & \multirow{2}{*}{$\begin{array}{c}\text { ATC-40 } \\
(1996)\end{array}$} & \multirow{2}{*}{$\begin{array}{c}\text { CSA-S6 } \\
(2006) \\
\text { AASHTO } \\
(1999) \\
\text { B }\end{array}$} & \multirow{2}{*}{$\begin{array}{c}\text { AASHTO } \\
(2014) \\
\text { Eq. } 4 \\
n=0.3 \\
B\end{array}$} & \multirow{2}{*}{$\begin{array}{c}\text { EC 8: } \\
\text { Part 2 } \\
\text { (1996) } \\
1 / \eta\end{array}$} & \multirow{2}{*}{$\begin{array}{c}\text { EC 8: } \\
\text { Part 2 } \\
\text { (2005) } \\
1 / \eta\end{array}$} \\
\hline & A Region & V Region & & & & & & \\
\hline 2 & 0.77 & & & & 0.80 & 0.76 & 0.82 & 0.84 \\
\hline 5 & 1.00 & 1.00 & 1.00 & 1.00 & 1.00 & 1.00 & 1.00 & 1.00 \\
\hline 10 & 1.29 & 1.22 & 1.19 & 1.22 & 1.20 & 1.23 & 1.21 & 1.22 \\
\hline 20 & 1.81 & 1.54 & 1.56 & 1.54 & 1.50 & 1.52 & 1.49 & 1.58 \\
\hline 30 & & 1.82 & 1.89 & 1.82 & 1.70 & 1.71 & 1.70 & 1.87 \\
\hline 40 & & 2.08 & & 2.08 & 1.90 & 1.87 & 1.87 & 2.12 \\
\hline 50 & & & & & 2.00 & 2.00 & 2.02 & 2.35 \\
\hline
\end{tabular}

Table 2: Structural parameters

\begin{tabular}{cc}
\hline Bridge Parameter & Values \\
\hline$R$ & $4,16,28,40,52$ \\
$T_{e}$ & $0.25,0.5,0.75,1.0 \mathrm{~s}$ \\
& $\xi\left(T_{e}\right)=0 \%, 2 \%, 5 \% ;$ \\
$\xi$ & $\xi\left(T_{\text {eff }}\right)=2 \%, 5 \%$ \\
$\alpha$ & {$[0.01,0.05,0.10$} \\
\hline
\end{tabular}

Table 3: Upper bound of a 95\% confidence interval for $u_{N L T H} / u_{\text {code }}(\alpha=0.01)$

\begin{tabular}{lccc}
\hline & $\bar{x}$ & $\sigma$ & $x$ \\
\hline WNA: Eq. 4 with $\mathrm{n}=0.3$ & 0.99 & 0.46 & 1.01 \\
ENA: Eq. 4 with $\mathrm{n}=0.3$ & 1.30 & 0.49 & 1.32 \\
ENA: Eq. 4 with $\mathrm{n}=0.2$ & 0.98 & 0.37 & 1.00 \\
\hline
\end{tabular}




\section{List of Figures:}

Fig. 1. Equivalent Linearization Method: a) Transformation of Nonlinear Bilinear System to Equivalent Linear System with Equivalent Damping; b) Typical Isolated Bridge in Laterally Displaced Configuration; and c) Equivalent Linearization Method

Fig. 2. Damping reduction coefficients specified by codes

Fig. 3. Design and individual spectra for time histories in Vancouver and Montreal

Fig. 4. Design and mean spectra for time histories in Vancouver and Montreal

Fig. 5. Computed vs code-specified damping coefficients $B$ for: a) WNA; b) ENA

Fig. 6. Peak displacements from NLTHA versus displacement estimates obtained using the CSA-S6 simplified method with damping coefficients from Eq. $4(n=0.3)$ for: a) WNA; b) ENA

Fig. 7. Probability density functions of the ratios between the peak displacements from nonlinear time history analyses (NLTHA) and peak displacements obtained using the CSA-S6 simplified method - Eq. 4 with $n=0.3$

Fig. 8. Ratios of peak displacements from NLTH analysis and code simplified method as a function of equivalent damping for: a) WNA; b) ENA

Fig. 9. Response of SDOF from NLTHA and LTHA (ATK: E6C1-33) a) displacement time history; b) hysteretic and linear responses

Fig. 10. Bilinear responses: a) Response with shift of the oscillation center reflecting actual nonlinear response; b) Idealized response centered about original oscillation center as assumed in the code simplified method

Fig. 11. Ratios of peak displacements from NLTH analysis and code simplified method plotted against $u_{\text {code }} / S_{d}$ for: a) WNA; b) ENA

Fig. 12. Variation of equivalent damping with effective period

Fig. 13. Ratios of peak displacements from NLTH analysis and code simplified method as a function of effective period for: a) WNA; b) ENA

Fig. 14. Coefficient of variation for equivalence ratio with $T_{\text {eff }}$ 
(a)

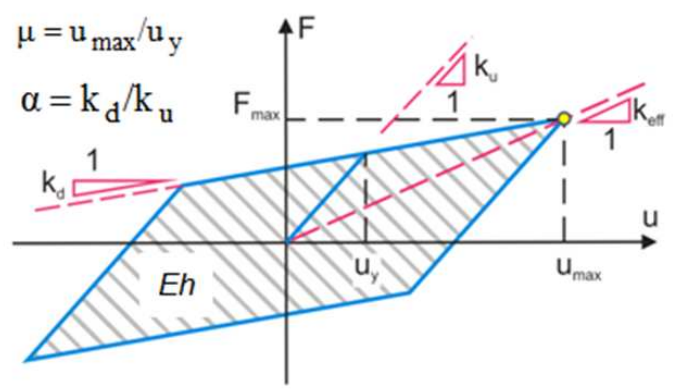

(b)

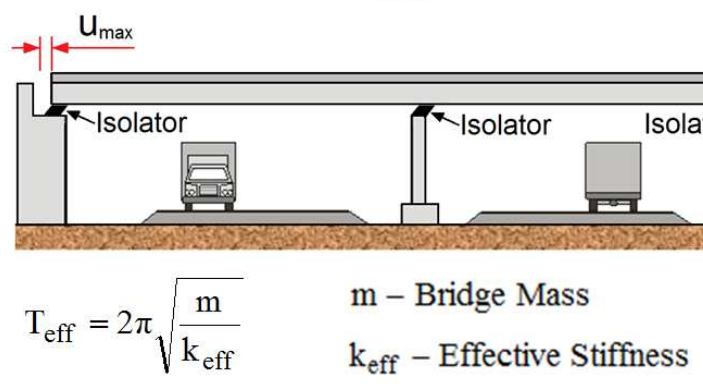

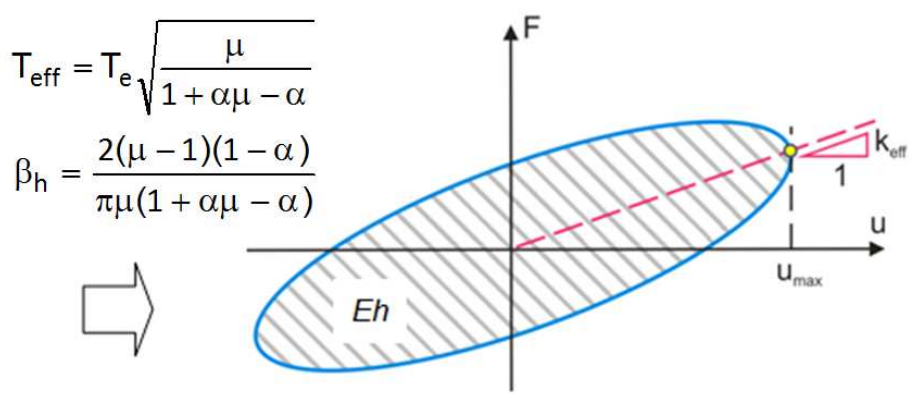

(c)

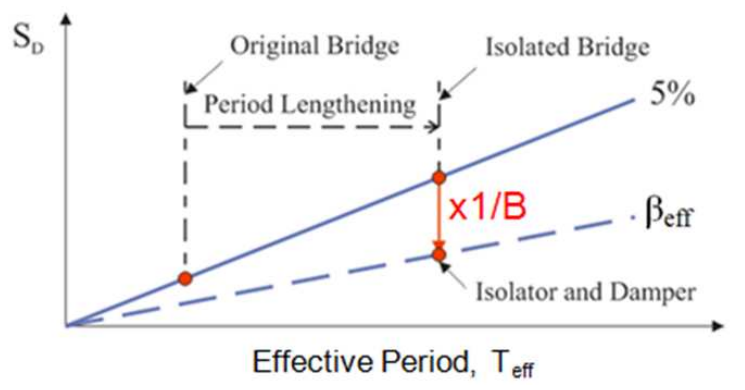




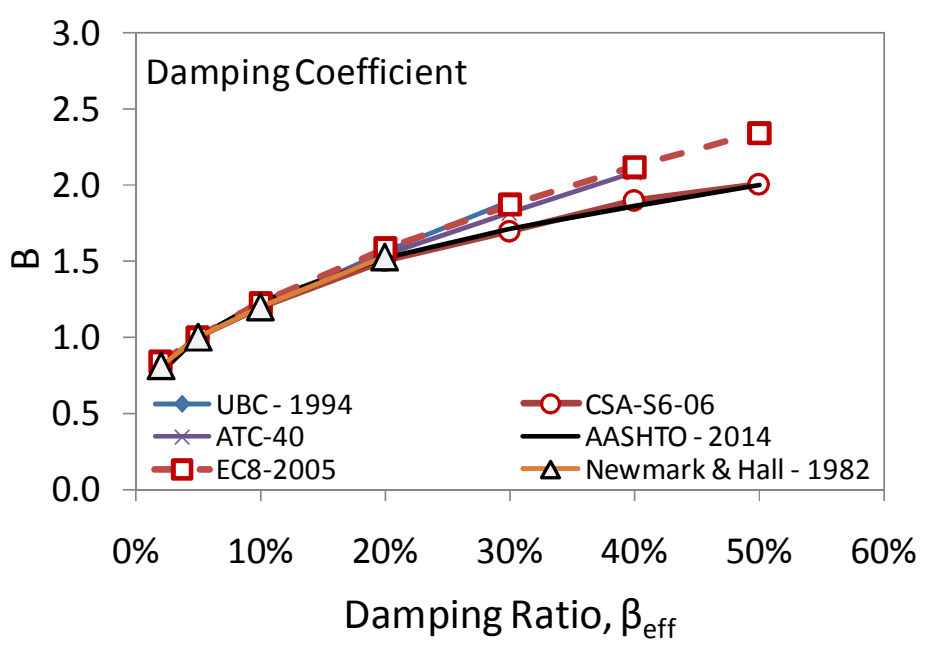

https://mc06.manuscriptcentral.com/cjce-pubs 

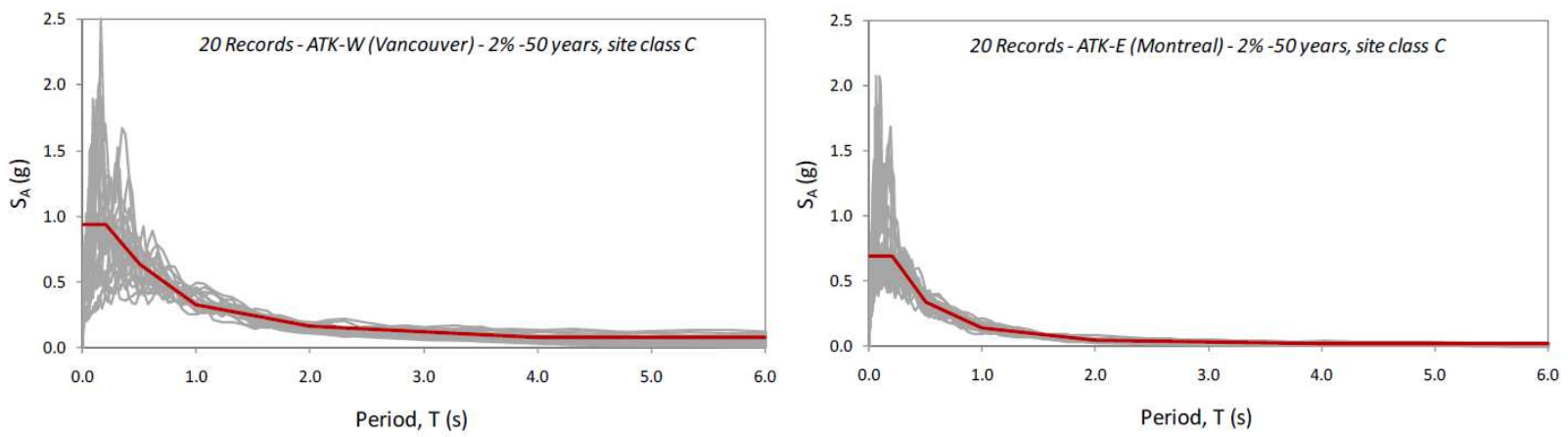

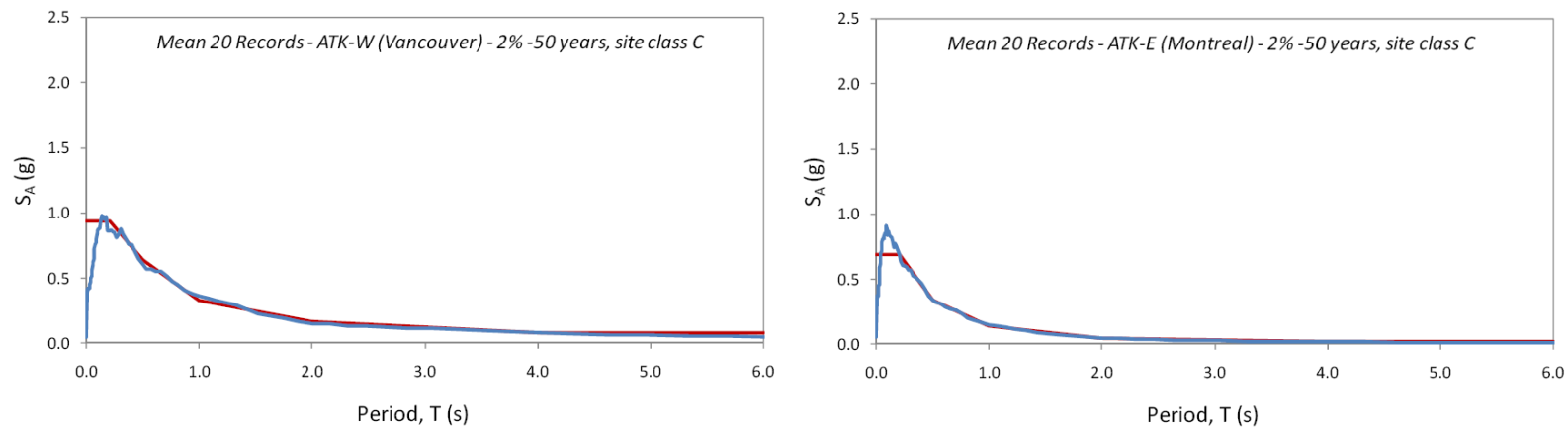

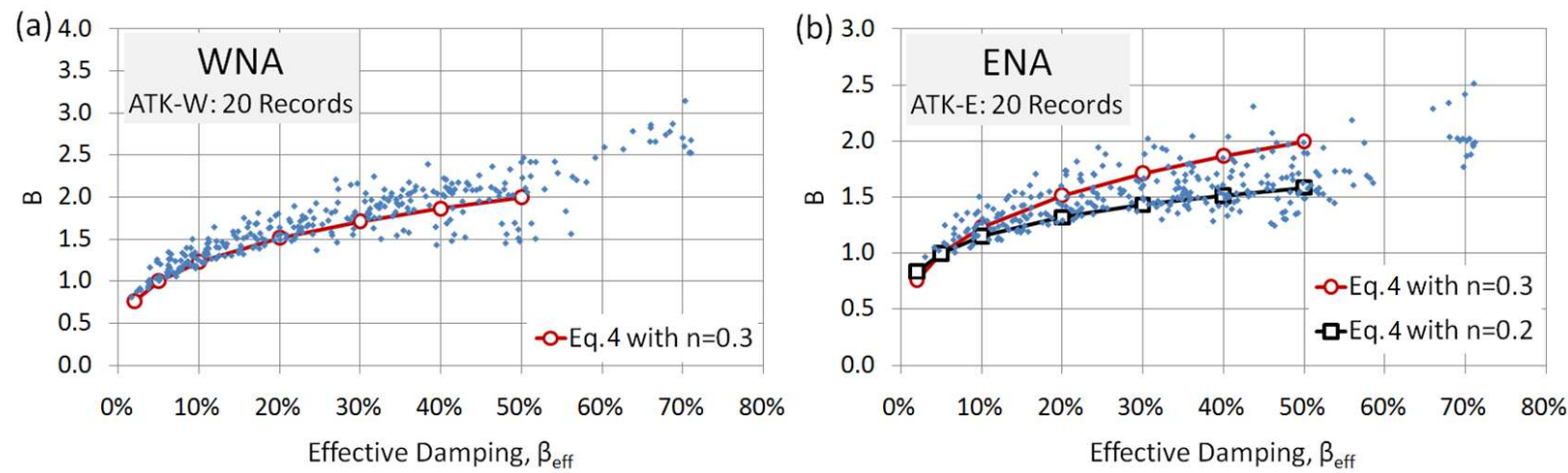
(a)

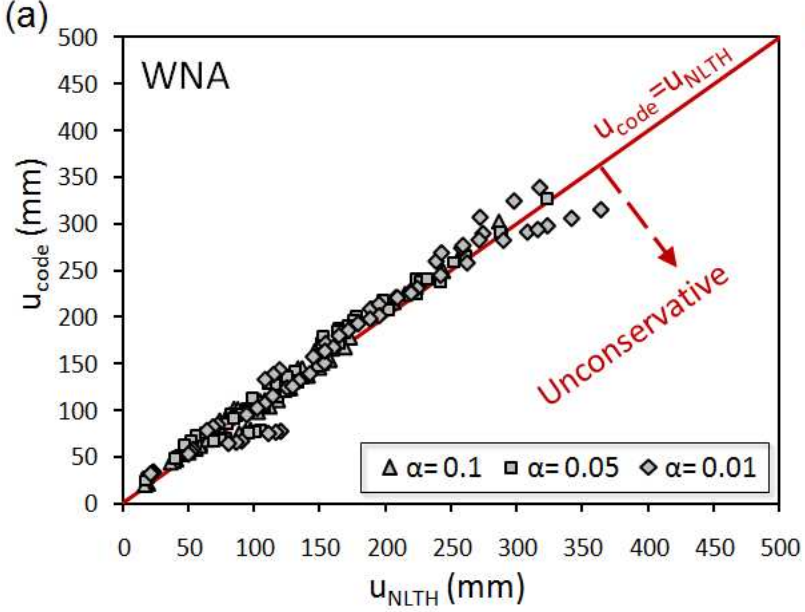

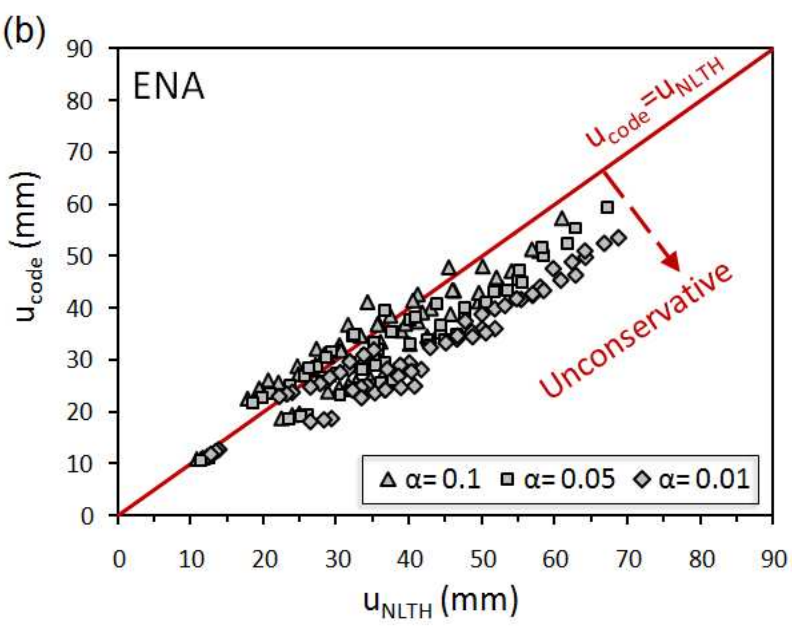



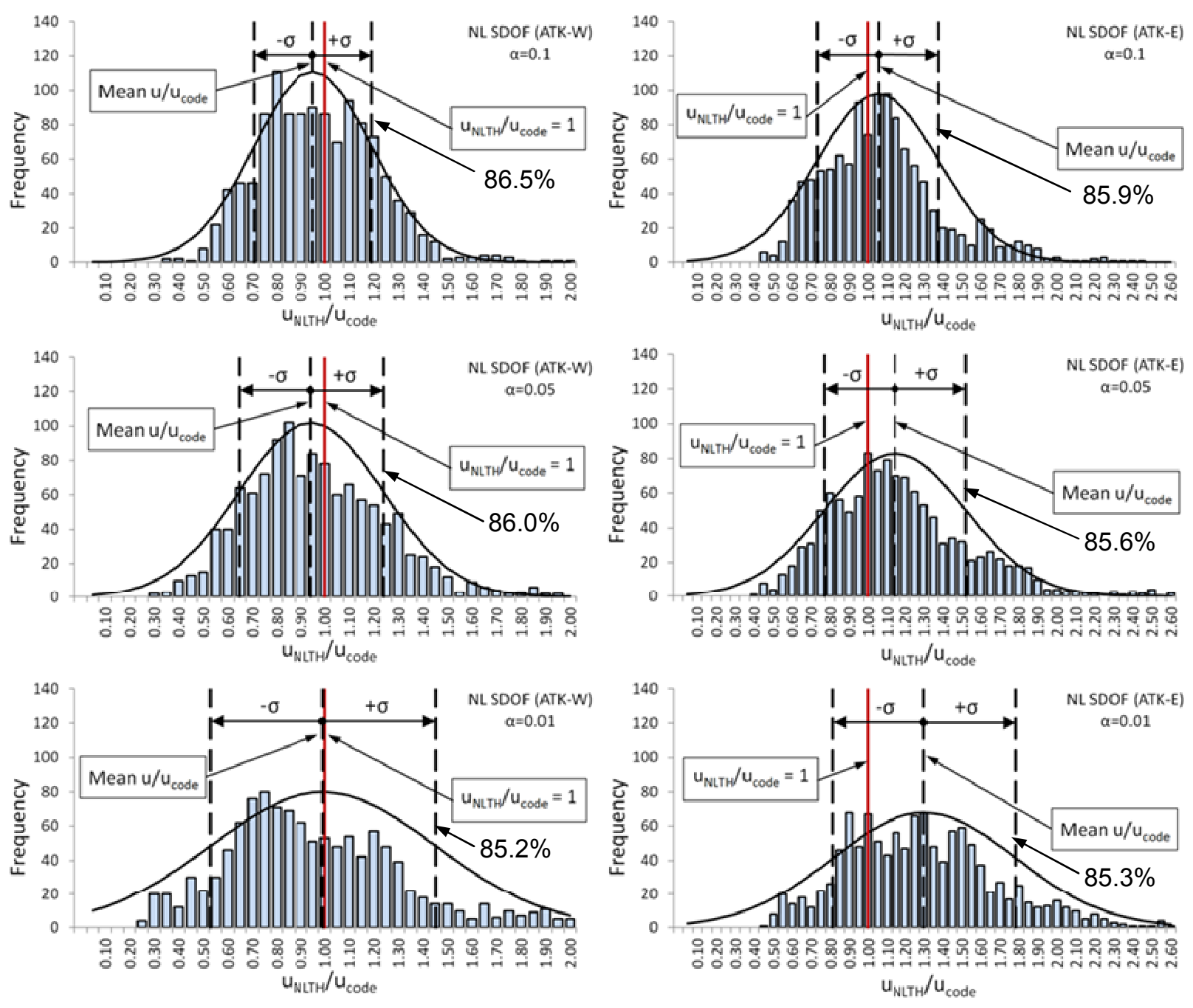

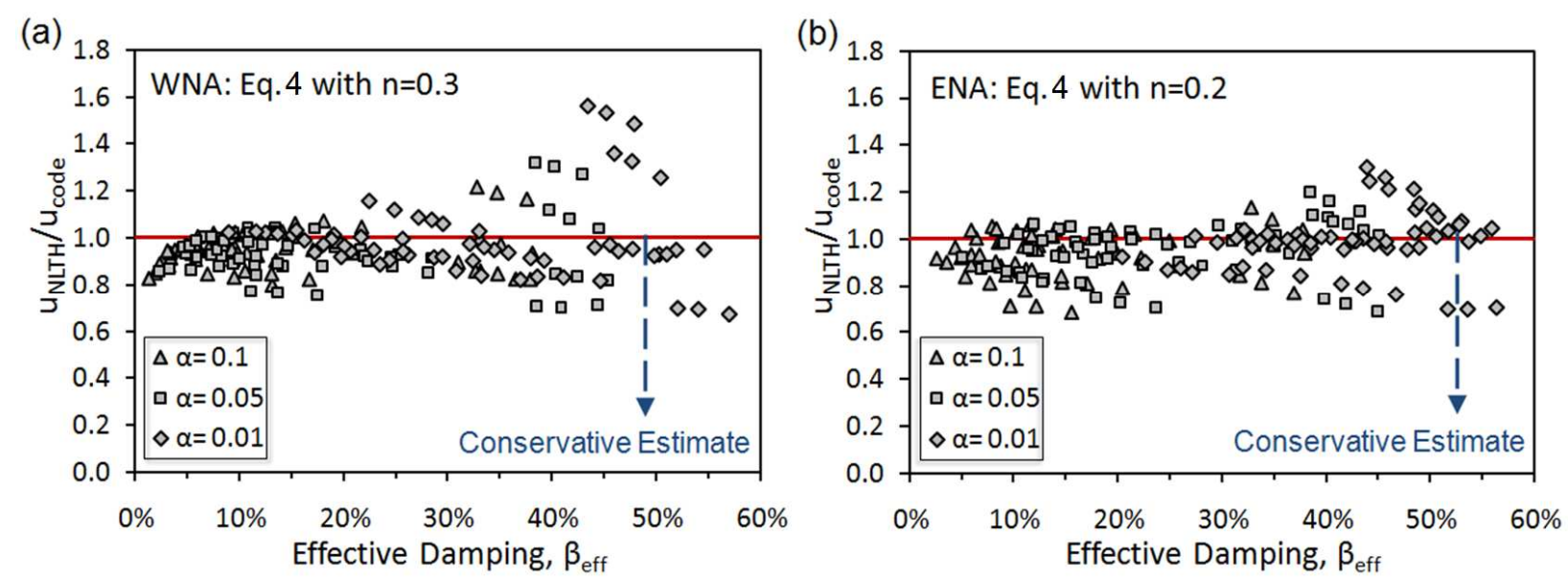
(a)

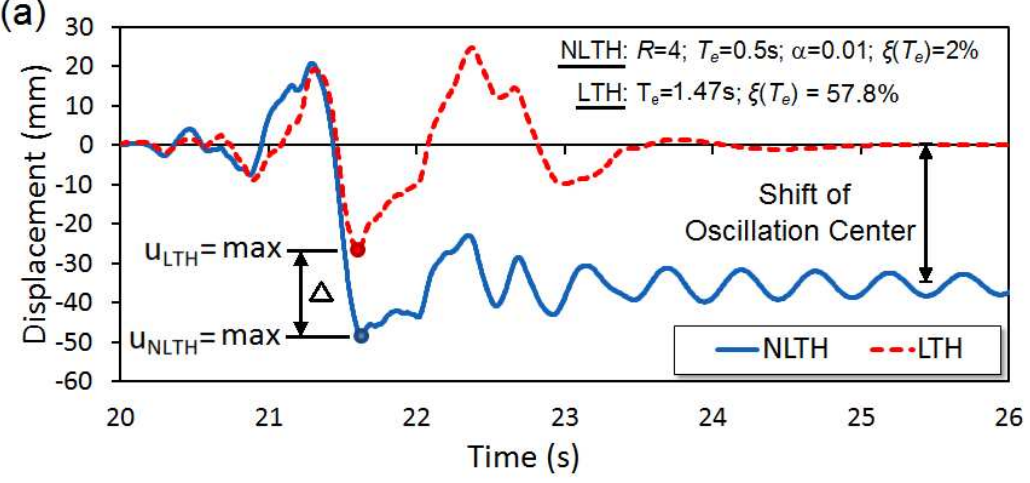

(b) 30

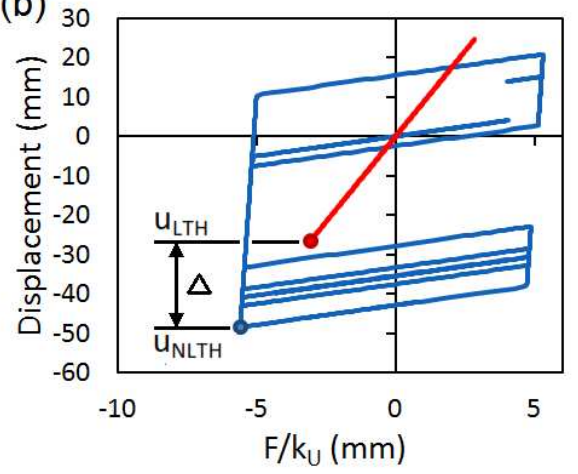




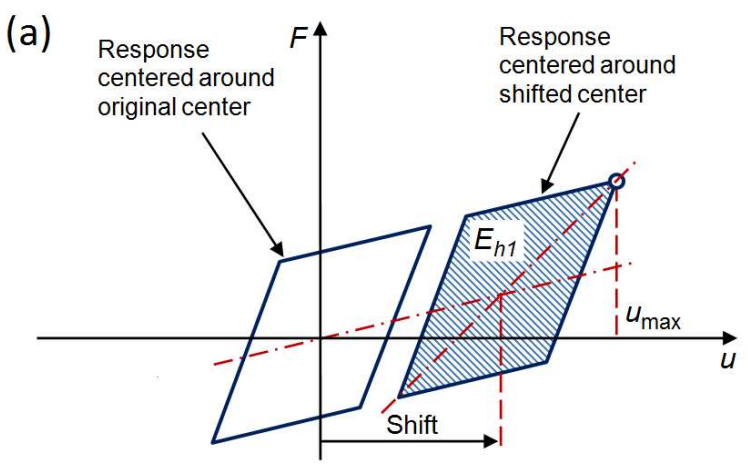

(b)

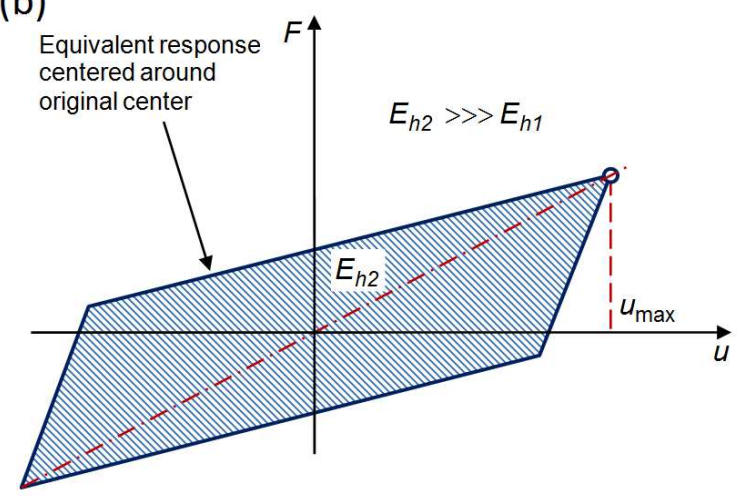



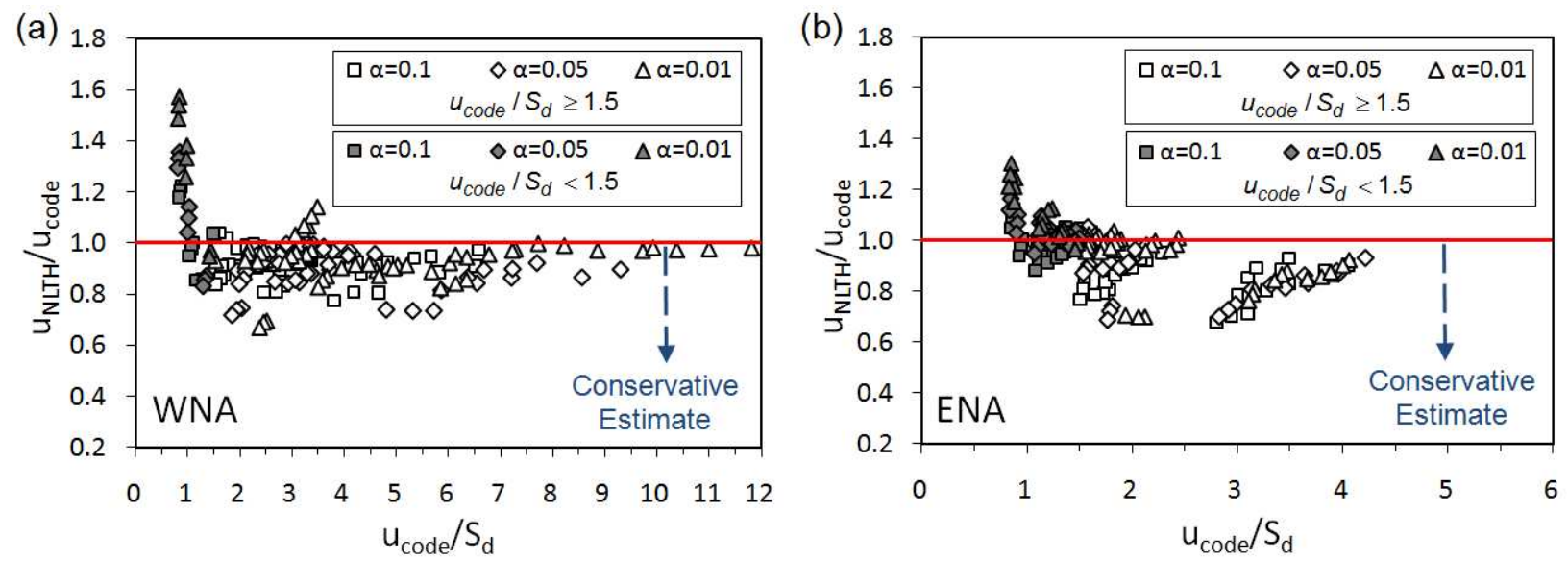


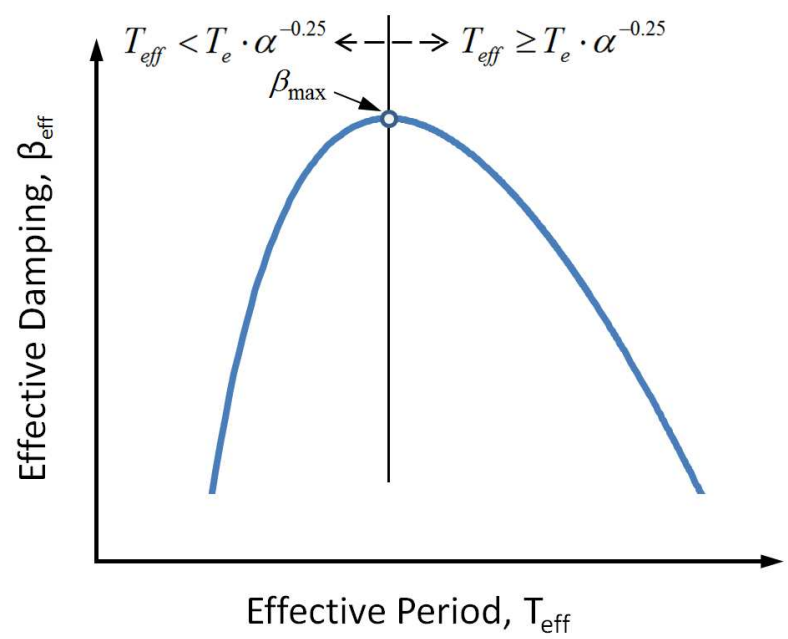

https://mc06.manuscriptcentral.com/cjce-pubs 

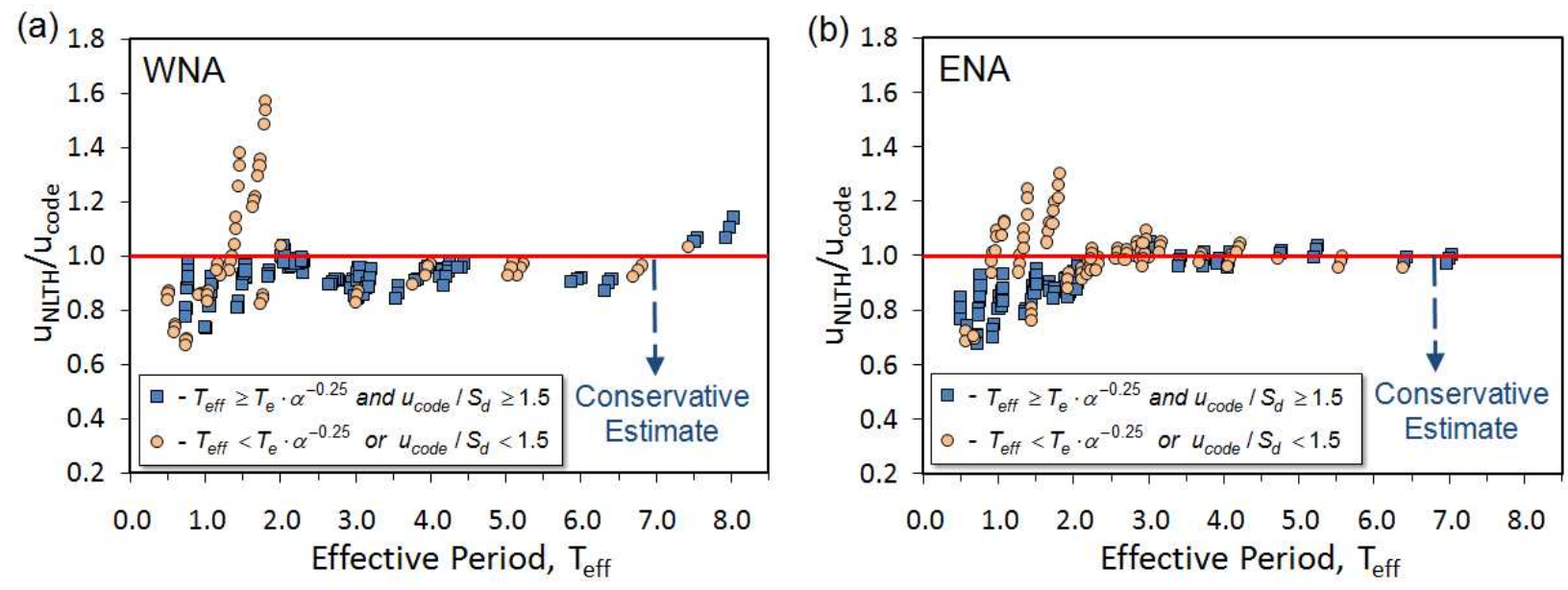

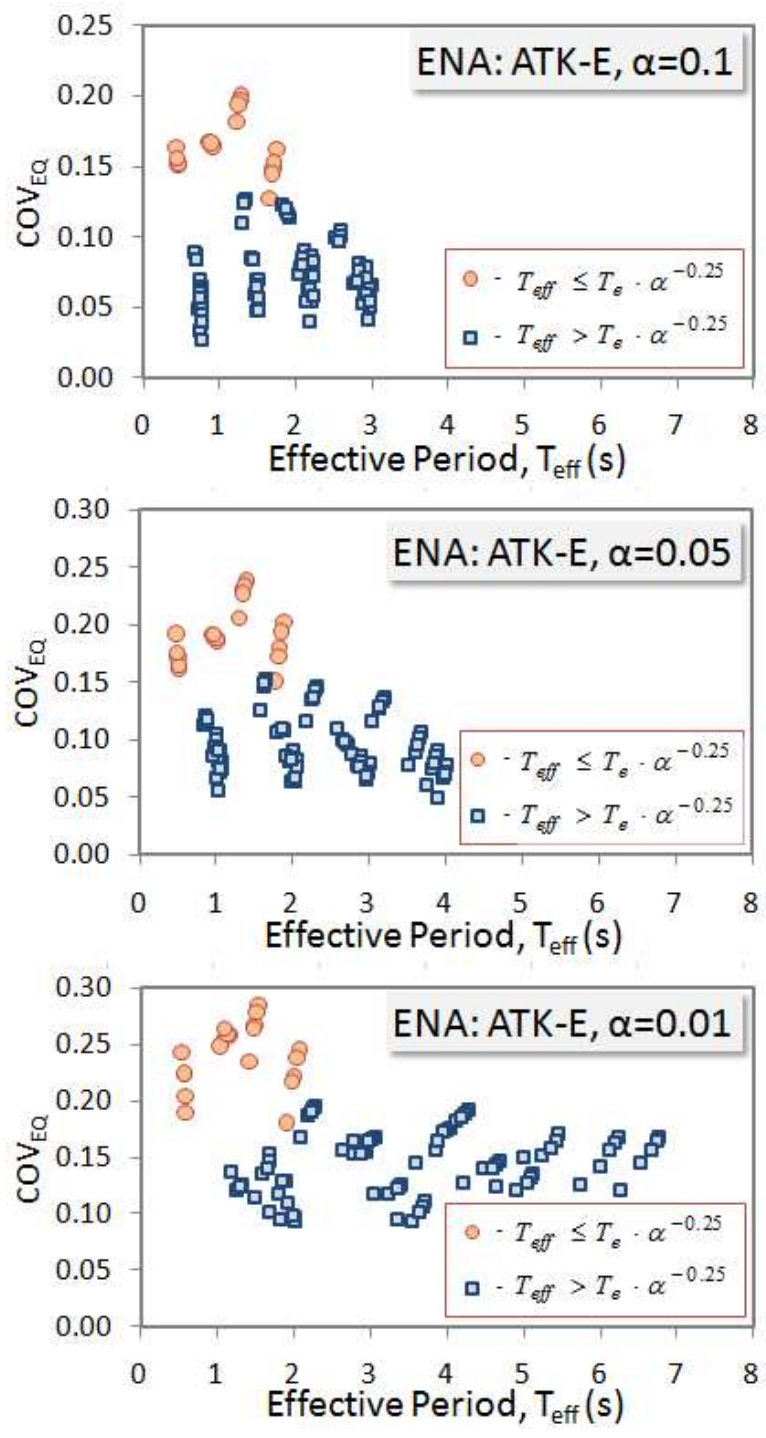

https://mc06.manuscriptcentral.com/cjce-pubs 